\title{
Numerical Study on Static Interaction of Closely Spaced Horizontal Square or Rectangular Ground Anchors in $c$ - $\phi$ Soil
}

\author{
Priyanka Ghosh $^{1} \cdot$ Ramdeo Kumar $^{1}$
}

Received: 15 September 2015/Accepted: 1 October 2015/Published online: 17 November 2015

(C) Springer International Publishing Switzerland 2015

\begin{abstract}
In the present study, an effort is made to explore the static interaction of two closely-spaced horizontal square or rectangular ground anchors embedded in homogenous $c-\phi$ soil deposit at different depths. The analysis is performed by using three dimensional finite difference program $F L A C^{3 D}$. Each anchor is subjected to equal displacement to obtain the ultimate uplift capacity. The soil is assumed to obey the Mohr-Coulomb failure criterion. The behavior of single isolated anchor is obtained first to explore the interaction effect between two nearby anchors. A parametric study is performed by varying the clear spacing $(S)$ between the anchors at different embedment ratios $(\lambda)$. The interaction phenomenon of two closely placed anchors is expressed in terms of the efficiency factor $\left(\xi_{\mathrm{u}}\right)$ at different clear spacing between the anchors.
\end{abstract}

Keywords Interaction effect - Numerical modeling · Ground anchors · Plasticity · Uplift capacity

\section{List of Symbols}

$B \quad$ Width of anchor (m)

$D$ Depth of embedment of anchor (m)

E Modulus of elasticity of soil $\left(\mathrm{kN} / \mathrm{m}^{2}\right)$

$L \quad$ Length of anchor (m)

$P \quad$ Uplift load of anchor $(\mathrm{kN})$

$P_{\mathrm{u}} \quad$ Ultimate uplift capacity of isolated anchor $(\mathrm{kN})$

$P_{\mathrm{u}}^{\prime} \quad$ Ultimate uplift capacity of interacting anchor $(\mathrm{kN})$

$S \quad$ Clear spacing between two anchors (m)

$S_{\max } \quad$ Maximum effective clear spacing (m)

Priyanka Ghosh

priyog@iitk.ac.in

1 Department of Civil Engineering, Indian Institute of Technology, Kanpur, Kanpur 208 016, India $c_{\mathrm{u}} \quad$ Undrained cohesion of soil $\left(\mathrm{kN} / \mathrm{m}^{2}\right)$

$\delta \quad$ Vertical displacement of anchor (m)

$\phi \quad$ Angle of internal friction of soil (degrees)

$\gamma \quad$ Unit weight of soil $\left(\mathrm{kN} / \mathrm{m}^{3}\right)$

$\lambda \quad$ Embedment ratio $=D / B$

$v \quad$ Poisson's ratio

$\xi_{\mathrm{u}} \quad$ Efficiency factor with respect to pullout capacity

\section{Introduction}

Ground anchors are inevitable to a number of geotechnical engineering applications such as support of transmission towers, retaining walls, bridges, as well as structures subject to buoyancy effects. In recent times, rapid urbanization coupled with scarcity of land force several structures supported by such ground anchors to come up ever closer to each other, which may sometime cause severe instability to the structures from both strength and serviceability point of view due to close interaction. Hence, the determination of interaction of closely spaced horizontal ground anchors is found to be quite sensible investigation as it might cause major catastrophe. A number of investigations have been performed by several researchers to predict the uplift resistance of single isolated anchor with the help of different numerical as well as experimental investigations [1-13]. However, in a number of situations, anchors may be placed in a group to generate the necessary pullout resistance. It can be noted from the literature that not much attention has been paid by the researchers to determine the response of a group of plate anchors. The effect of interaction on the uplift capacity of a group of strip anchors under static condition has been studied by various researchers [1, 14-18], whereas Ghosh and Kumari [19] 

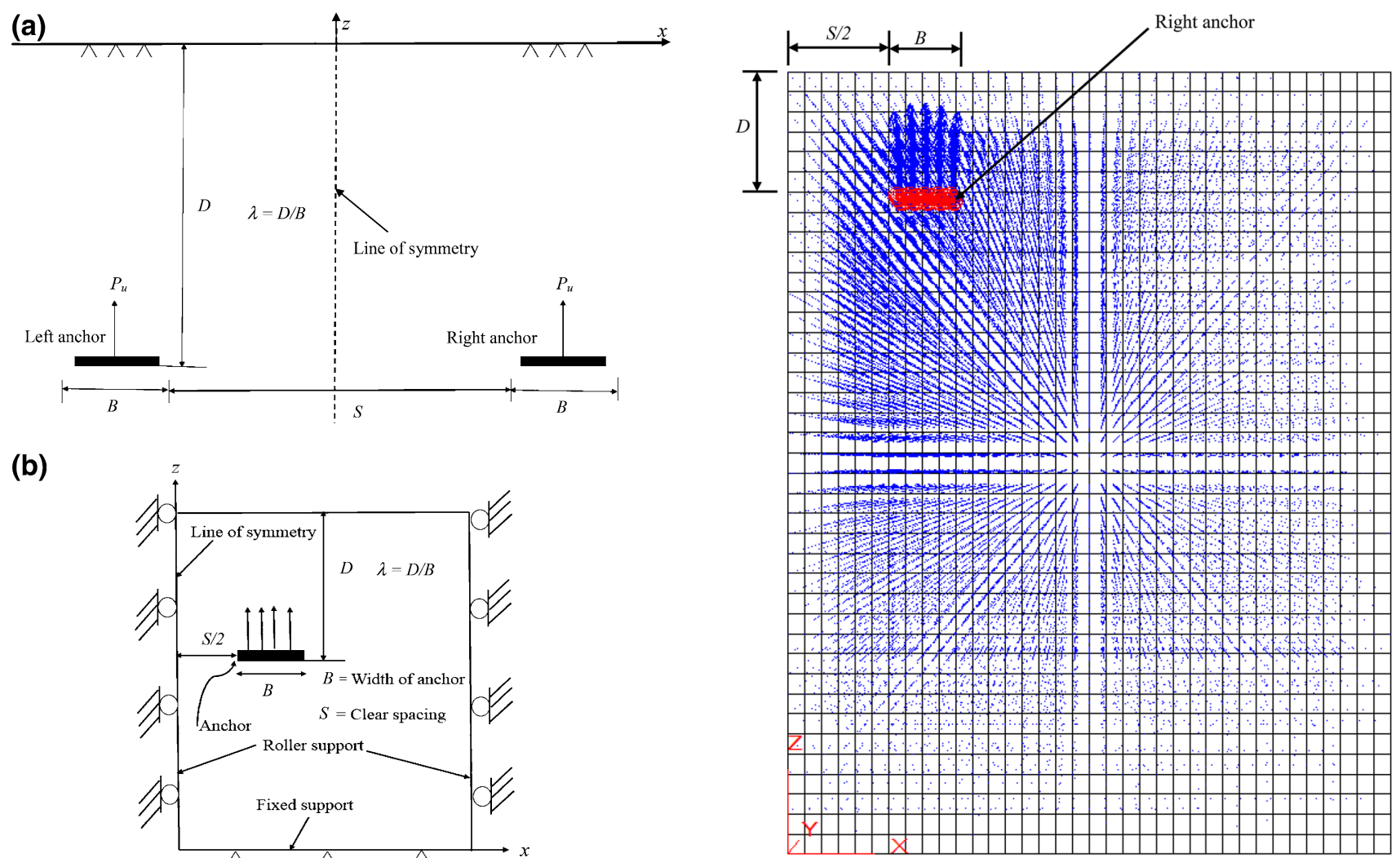

(b)

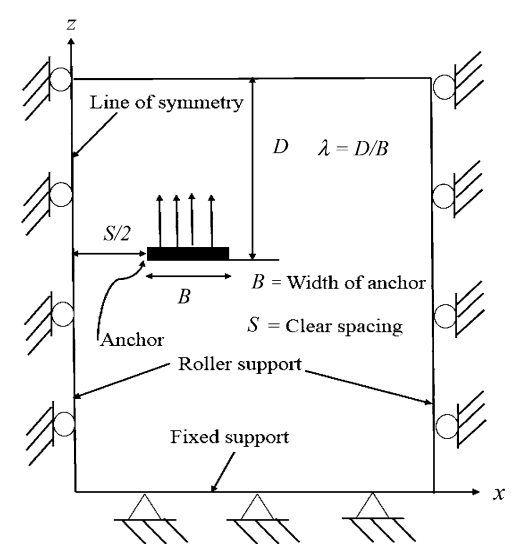

Fig. 1 Problem definition along with right half of failure domain and associated boundary conditions

Table 1 Physical properties of different soil deposits [19]

\begin{tabular}{lll}
\hline Physical properties & Deposit-1 & Deposit-2 \\
\hline Modulus of elasticity, $E\left(\mathrm{kN} / \mathrm{m}^{2}\right)$ & $2.06 \times 10^{3}$ & $8.02 \times 10^{3}$ \\
Unit weight, $\gamma\left(\mathrm{kN} / \mathrm{m}^{3}\right)$ & 17 & 18 \\
Undrained cohesion, $c_{\mathrm{u}}\left(\mathrm{kN} / \mathrm{m}^{2}\right)$ & 19.4 & 75.7 \\
Angle of internal friction, $\phi\left({ }^{\circ}\right)$ & 25 & 29 \\
\hline
\end{tabular}

have explored the interaction of closely spaced strip anchors under seismic condition. However, in majority of the practical situations three dimensional (square or rectangular) plate anchors are the most preferred option. Therefore, the investigation on the static interaction of closely spaced square or rectangular anchors demands some attention.

In the present analysis, an effort is made to explore the static interaction effect of two closely spaced horizontal square or rectangular ground anchors embedded in dry homogenous $c-\phi$ soil deposit at different depths. The analysis is performed by using $F L A C^{3 D}$ [20], which is a three-dimensional explicit finite-difference program for engineering mechanics computation. The soil is assumed to obey the Mohr-Coulomb failure criterion with non-linear

Fig. 2 Displacement vectors for interacting anchors at $D / B=1$, $S / B=2$ in deposit-1

failure envelope. The load-displacement response as well as the efficiency factor $\left(\xi_{\mathrm{u}}\right)$ of the interacting anchors at different clear spacing, $S$ and embedment ratio, $\lambda$ are reported in the present paper.

\section{Definition of Problem}

Two closely spaced embedded square $(B \times B)$ or rectangular $(B \times L)$ plate anchors are placed horizontally in a dry homogeneous soil deposit as shown in Fig. 1. Each anchor is placed with its longest dimension $(L)$ along the $y$ direction (normal to the plane) and loaded simultaneously to the failure. The objective is to determine the the ultimate uplift capacity $\left(P_{\mathrm{u}}\right)$ of the interacting anchor plates and the efficiency factor $\left(\xi_{\mathrm{u}}\right)$. The $x$ and $z$ directions as shown in Fig. 1 are considered as positive.

\section{Analysis}

\section{Materials}

Two different homogeneous soil deposits (deposit-1 and deposit-2) extending up to a depth of $11.7 \mathrm{~m}$ followed by 
the bedrock is considered in the present study. Table 1 lists the material properties of deposit- 1 and deposit-2, adopted from layer-1 and layer-2 of the subsoil respectively as considered by Ghosh and Kumari [19], and Ghosh [21]. The Poisson's ratio (v) of soil is considered as 0.3 for both the deposits. The water table is found to be at great depth, which is assumed to have no significant impact on the analysis. The Young's modulus, density and Poisson's ratio of the steel anchor plate are considered as $2.1 \times 10^{8} \mathrm{kN} /$ $\mathrm{m}^{2}, 7.8 \times 10^{3} \mathrm{~kg} / \mathrm{m}^{3}$ and 0.25 , respectively. The thickness of the anchor plates is chosen as $0.1 \mathrm{~m}$ to provide sufficient rigidity against the vertical pullout.

\section{Numerical Modeling}

Three dimensional finite difference mesh has been created using brick elements available in $F L A C^{3 D}$ for two closely spaced embedded anchors (left and right). In the analysis, shell type structural element has been considered to model the anchor plate, which is three-noded Discrete Kirchoff Triangle (DKT) plate bending element. It is worth mentioning that the DKT plate bending element is a threenodded plate element with three degrees of freedom at each
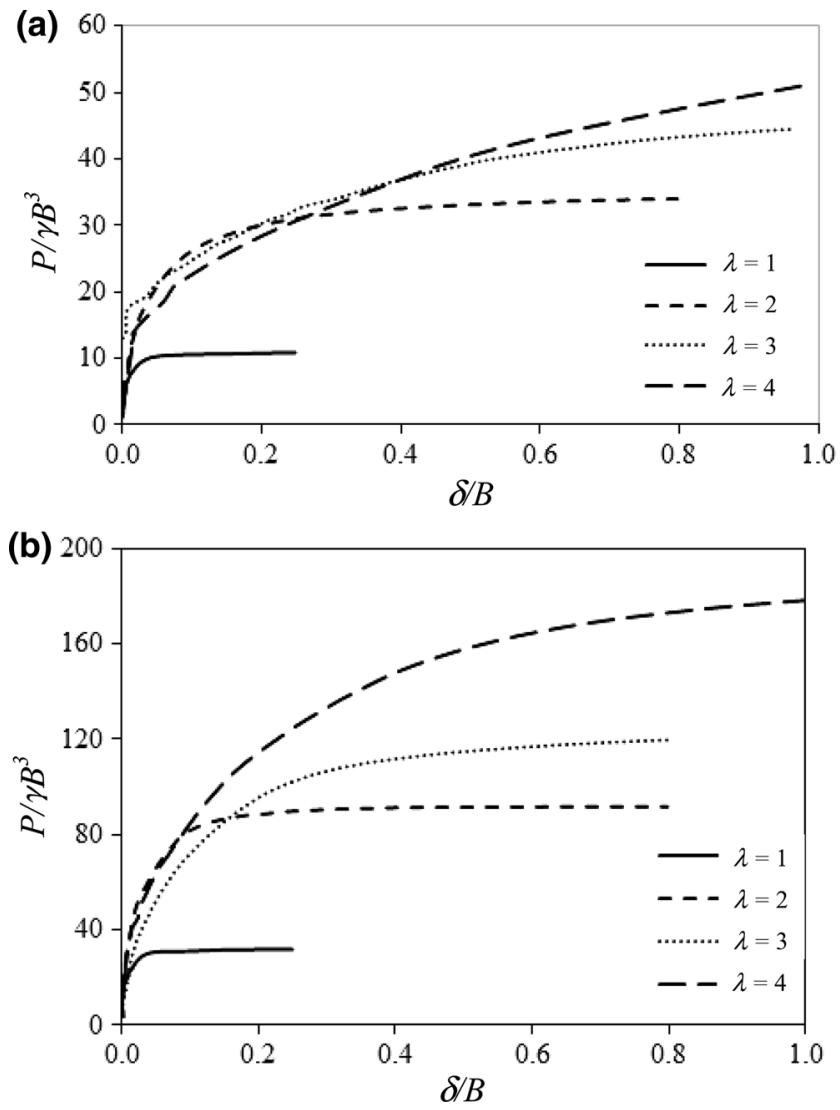

Fig. 3 Normalized load-displacement curves for isolated square anchor in a deposit-1, b deposit-2 for different $\lambda$
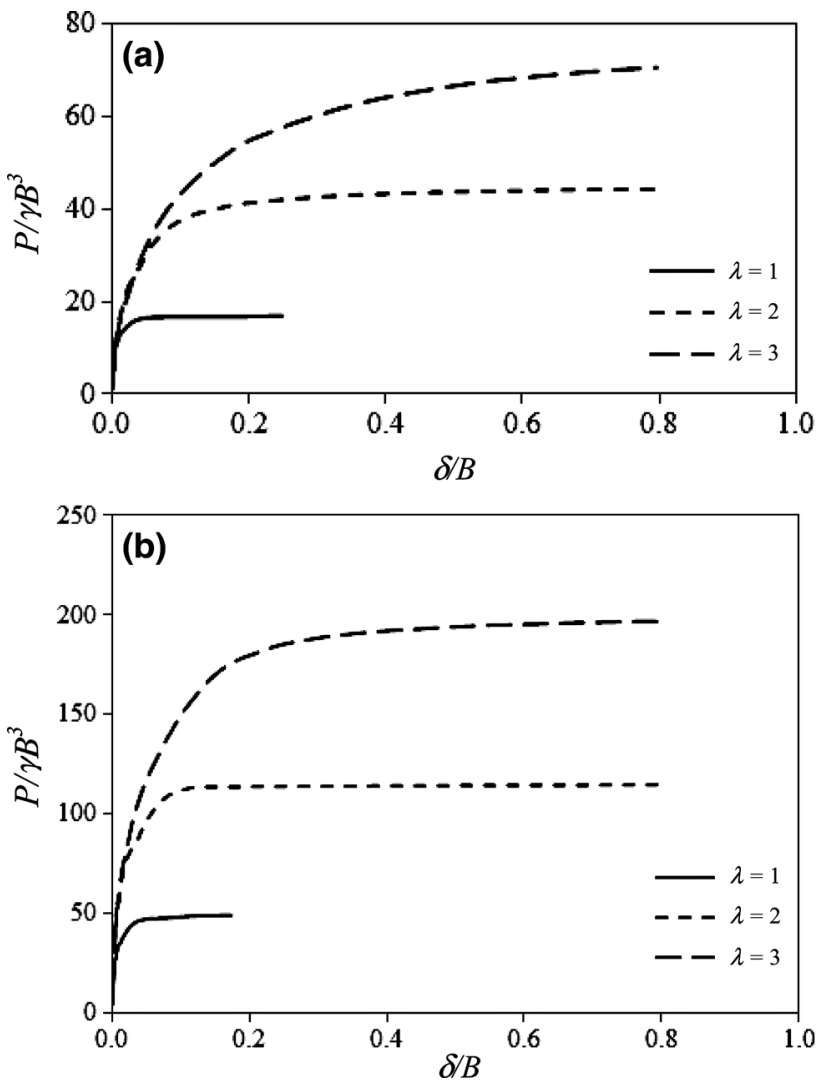

Fig. 4 Normalized load-displacement curves for isolated rectangular anchor $(L / B=2)$ in a deposit-1, $\mathbf{b}$ deposit-2 for different $\lambda$

node i.e., one translational and two rotational components. The details of the mesh and placement of interacting anchor in deposit-1 at $D / B=1, S / B=2$ is shown in Fig. 2. The ultimate pullout resistance of the isolated as well as interacting anchors is obtained by prescribing same amount of uniform displacement at the anchor plates. The displacement vectors for interacting anchor in deposit-1 at $D / B=1, S / B=2$ is shown in Fig. 2. First, the ultimate pullout capacity of isolated anchor is obtained and later, the static interaction effect of two nearby anchors in terms of the ultimate uplift capacity is determined at different magnitude of $S$. The sensitivity analysis is performed to determine the optimum domain size by varying the lateral dimension of the failure domain from $6 B$ to $8 B$ from the edge of the anchors along both $x$ and $y$ directions. Beyond the distance of $7 B$ from the edge of the anchor along both $x$ and $y$ directions, no significant variation in the ultimate uplift capacity of the anchor plates is observed. Therefore, in the present study the failure domain with $7 B$ distance from the edge of the anchor is considered in the lateral directions. However, the depth of the failure domain along the negative $z$ direction is extended up to the bedrock level irrespective of the type of anchor, which is $11.7 \mathrm{~m}$ below the ground surface $(z=0)$. It is worth noting here that the 

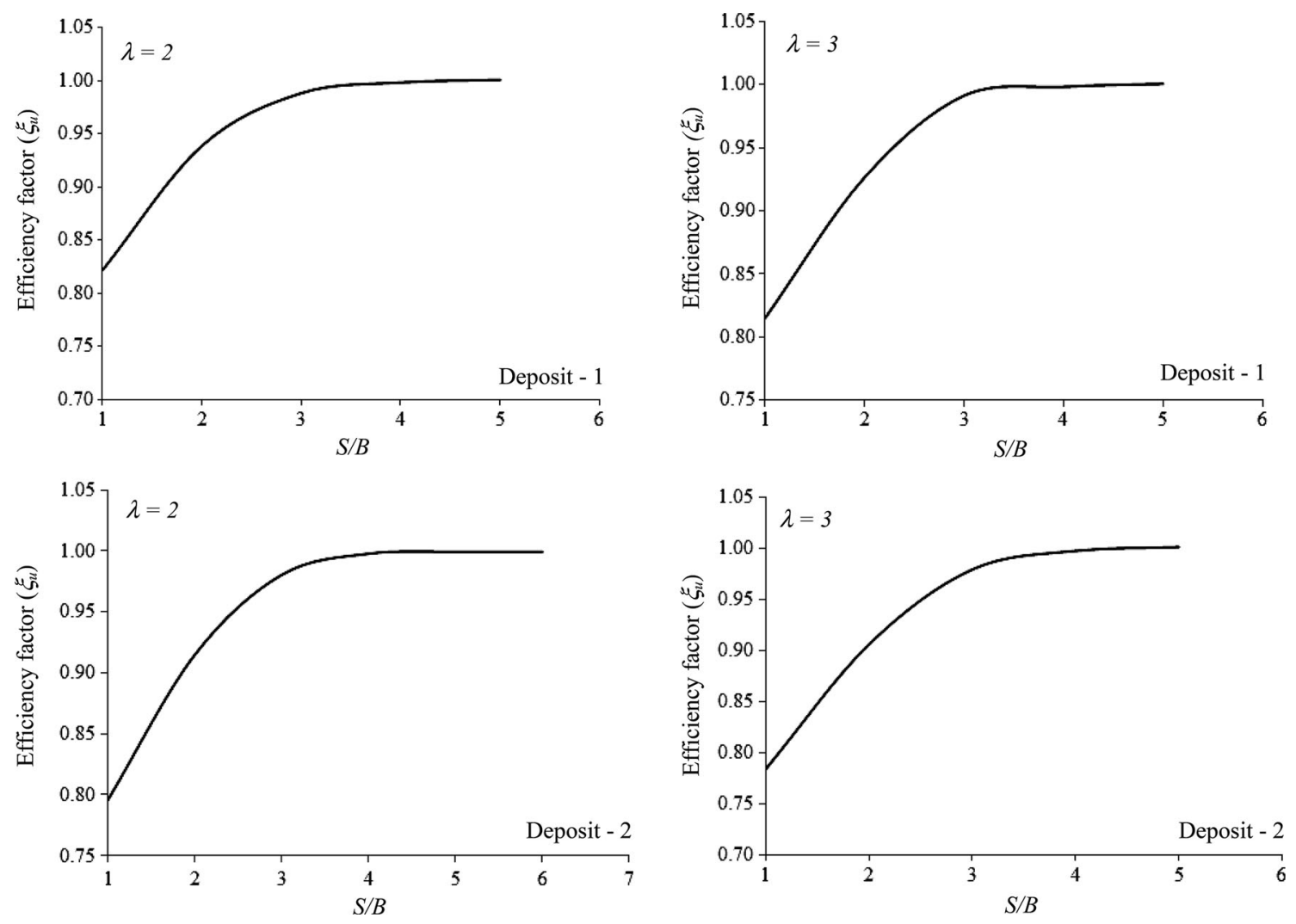

Fig. 5 Variation of $\xi_{\mathrm{u}}$ with $S / B$ for interacting square anchors at different deposits and $\lambda$
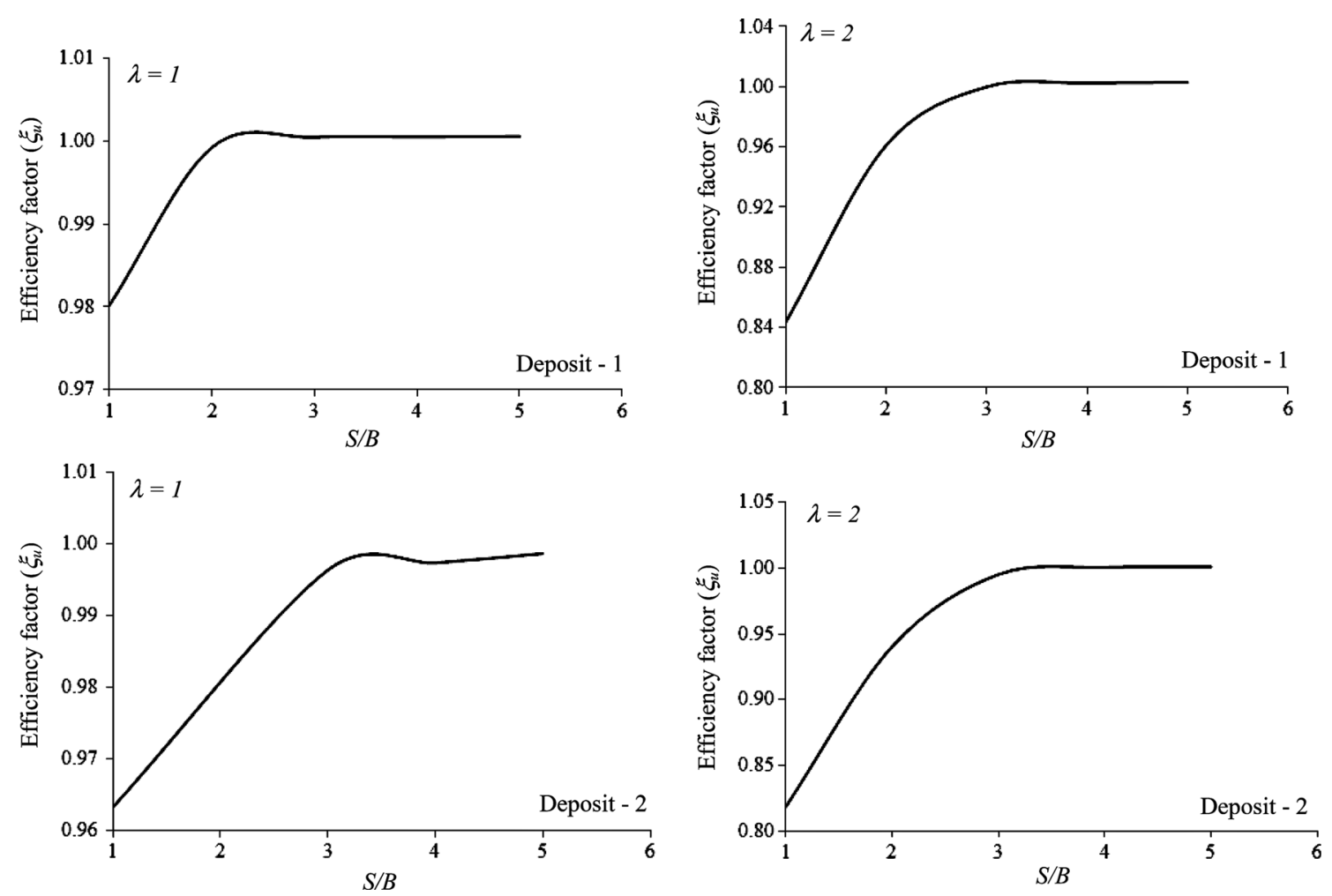

Fig. 6 Variation of $\xi_{\mathrm{u}}$ with $S / B$ for interacting rectangular $(L / B=2)$ anchors at different deposits and $\lambda$ 

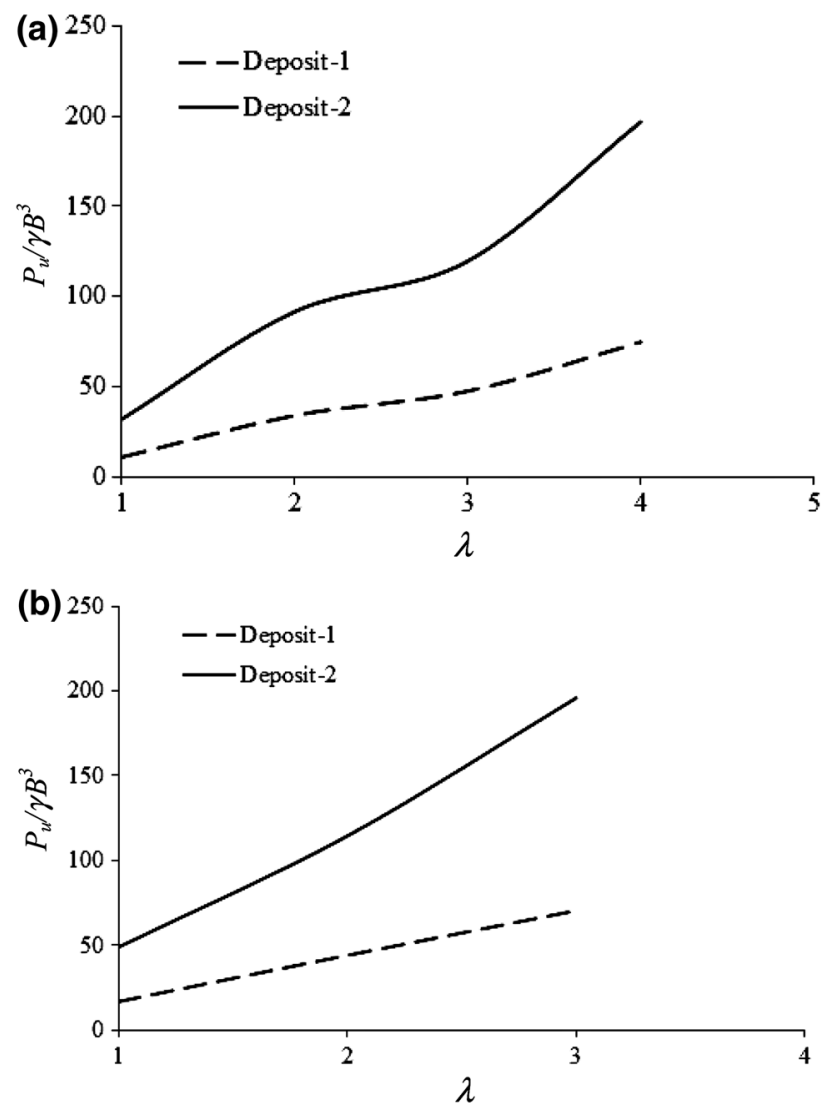

Fig. 7 Variation of normalized ultimate uplift capacity with $\lambda$ for isolated a square, b rectangular $(L / B=2)$ anchors in different soil deposits

analysis is carried out with half of the domain by taking the advantage of the symmetry of the problem. In the analysis, the soil is assumed to follow the Mohr-Coulomb failure criteria with non-linear failure envelope available in $F L A C^{3 D}$, whereas the steel anchors are assumed to be linear elastic material. During the analysis, the extreme side boundaries of the failure domain are kept fixed in the direction normal to the respective plane, whereas the bottom boundary is considered fixed in all directions.

\section{Results and Discussion}

Normalized load-displacement characteristics of an isolated square and rectangular $(L / \mathrm{B}=2.0)$ anchor in different deposits for various $\lambda$ are shown in Figs. 3 and 4 , respectively. It can be noted that the uplift load, $P$ of the anchors increases with increase in the vertical displacement of the anchor plate, $\delta$ and eventually becomes almost constant indicating the ultimate uplift capacity, $P_{\mathrm{u}}$. The magnitude of $P_{\mathrm{u}}$ always increases with increase in $\lambda$ irrespective of the type of anchor. A parameter, efficiency factor $\left(\xi_{\mathrm{u}}\right)$ with respect to the pullout capacity is introduced
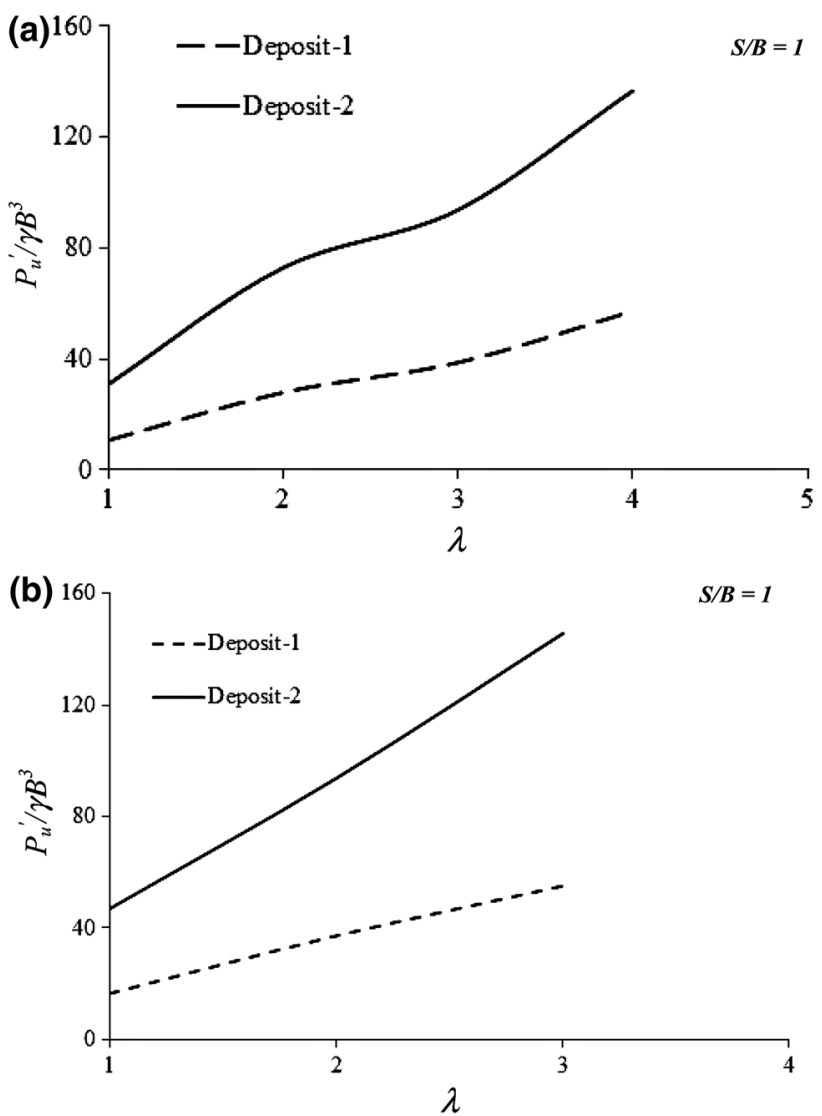

Fig. 8 Variation of normalized ultimate uplift capacity with $\lambda$ for interacting a square, b rectangular $(L / B=2)$ anchors in different soil deposits at $S / B=1$

to compare the uplift resistance of an interacting anchor with that of an isolated anchor, which can be defined as the ratio of the ultimate pullout capacity of an interacting anchor of a given width $(B)$ to that of an isolated anchor of the same size. The variation of $\xi_{\mathrm{u}}$ with $S / B$ for square and rectangular interacting anchors at different soil deposits and $\lambda$ is shown in Figs. 5 and 6, respectively. The study indicates that the magnitude of $\xi_{\mathrm{u}}$ increases with increase in $S / B$ ratio and eventually becomes equal to 1.0 at some maximum spacing, $S_{\max }$. It is worth noting here that the condition $\xi_{\mathrm{u}}=1.0$ indicates the behavior of single isolated anchor without any interaction. It can be also observed that the magnitude of efficiency factor is found to be lower than unity at closer spacing, which indicates reduction in the pullout resistance at lower spacing. This observation is very much unlike to that made by different researchers for interacting foundations. In Figs. 7 and 8, the variation of normalized ultimate uplift capacity with $\lambda$ for isolated and interacting square and rectangular anchors is shown for different soil deposits, respectively. It can be noted that the ultimate uplift capacity increases with increase in $\lambda$ for both square and rectangular isolated as well as interacting anchors. For a given embedment ratio, the ultimate uplift 

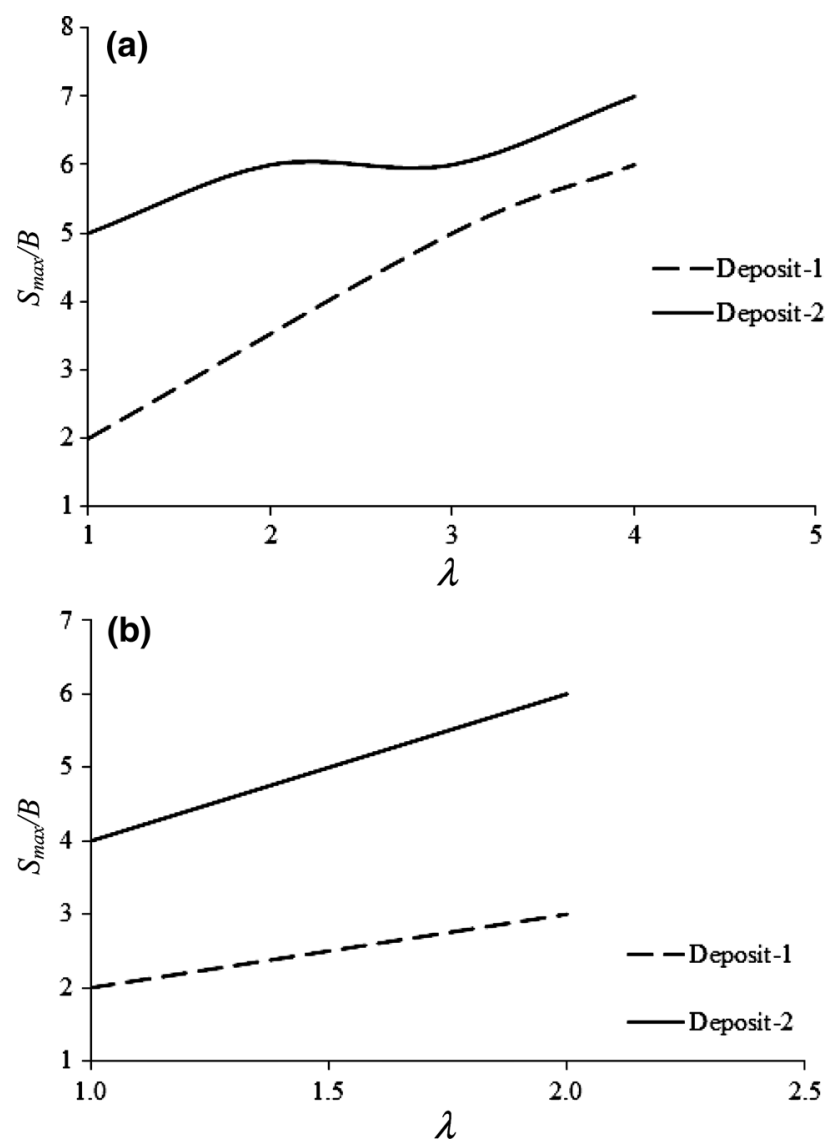

Fig. 9 Variation of $S_{\max } / B$ with $\lambda$ for interacting a square, b rectangular $(L / B=2)$ anchors in different soil deposits

Table 2 Comparison of $P_{\mathrm{u}}$ of isolated rectangular anchor at $\lambda=4$ in cohesionless soil as proposed by Singh and Mistri [22]

\begin{tabular}{ll}
\hline Theory & $P_{\mathrm{u}}(\mathrm{kN})$ \\
\hline Present analysis & 227.5 \\
Meyerhof and Adams [1] & 205.0 \\
Murray and Geddes [4] & 238.7 \\
\hline
\end{tabular}

capacity is found to be higher in deposit- 2 as compared to that in deposit- 1 . This distinctly indicates that the soil with higher density and modulus of elasticity exhibits higher uplift capacity. The magnitude of $P_{\mathrm{u}}^{\prime}$ is found to be higher for interacting rectangular anchors as compared to that of interacting square anchors at lower embedment ratio. However, the trend just becomes reverse at higher value of $\lambda$. This may be attributed to larger development of overlapped region in presence of interaction with increase in $\lambda$. It is worth mentioning here that in a particular deposit, the ultimate pullout capacity of interacting anchors can be obtained by:

$P_{\mathrm{u}}^{\prime}=\xi_{\mathrm{u}} P_{\mathrm{u}}$, where, the magnitude of $P_{\mathrm{u}}$ and $P_{\mathrm{u}}^{\prime}$ at different $\lambda$ can be obtained from Figs. 6 and 7, respectively.

Figure 9 presents the variation of $S_{\max } / B$ with $\lambda$ for interacting square and rectangular anchors in different deposits. It can be observed that $S_{\max }$ increases with increase in $\lambda$, which indicates that the domain of interaction increases with increase in the embedment ratio of the interacting anchors. It can also be seen that deposit-2 exhibits higher $S_{\max }$ than deposit-1, which shows that the soil deposit having higher density and modulus of elasticity displays significant interaction effect between the anchors up to a larger clear spacing.

\section{Comparison}

A number of investigations on the single isolated square and rectangular anchors under static condition are available in the literature; whereas the same for closely spaced square or rectangular anchors is scanty. Hence, the present results for interacting square or rectangular anchors could not be compared with any of the research works due to lack of availability of studies in the literature. However, for the comparison purpose, the present analysis is carried out with an isolated rectangular anchor resting on a homogeneous cohesionless soil deposit whose properties are reported by Singh and Mistri [22] as $E=3 \times 10^{4} \mathrm{kN} / \mathrm{m}^{2}, \gamma=20 \mathrm{kN} /$ $\mathrm{m}^{3}, \phi=40^{\circ}$ and $v=0.4$. In Table 2, the magnitude of the ultimate uplift capacity obtained from the present analysis for isolated rectangular anchor of $L=1 \mathrm{~m}$ and $B=0.5 \mathrm{~m}$ is compared with the value obtained from the theory proposed by Meyerhof and Adams [1], and Murray and Geddes [4]. The value of $P_{\mathrm{u}}$ of an isolated rectangular anchor obtained from the present analysis is found to match well with the result obtained from the theory of Meyerhof and Adams [1], and Murray and Geddes [4].

\section{Conclusions}

The static interaction effect of two nearby horizontal square or rectangular anchors placed in homogeneous $c-\phi$ soil medium at different embedment ratios is determined numerically. Based on the scope of the present investigation, the following conclusions can be made:

- The uplift capacity of anchors is observed to be strongly dependent upon the embedment ratio, which increases considerably with increase in $\lambda$.

- The amount of displacement required to attain the ultimate failure usually increases with increase in the embedment ratio.

- The magnitude of the efficiency factor, $\xi_{\mathrm{u}}$ is found to increase with increase in $S / B$ ratio and eventually 
becomes equal to 1.0 at some maximum spacing i.e. the magnitude of the ultimate uplift capacity of interacting anchors reduces quite extensively with decrease in the spacing between the anchors.

- The maximum spacing, $S_{\max }$ up to which the interaction effect between the anchors remains predominant, increases with increase in $\lambda$.

Acknowledgments The first author would like to acknowledge the financial support provided by the Department of Science and Technology (DST), India to carry out the present work through a sponsored research project (Ref No. SR/S3/MERC-021/2011 (G)).

\section{References}

1. Meyerhof GG, Adams SI (1968) The ultimate uplift capacity of foundations. Can Geotech J 5(4):225-244

2. Rowe RK, Davis EH (1982) The behaviour of anchor plates in clay. Geotechnique 32(1):9-23

3. Stewart W (1985) Uplift capacity of circular plate anchors in layered soil. Can Geotech J 22:589-592

4. Murray EJ, Geddes JD (1987) Uplift of anchor plates in sand. J Geotech Eng ASCE 113(3):202-214

5. Bouazza A, Finlay TW (1990) Uplift capacity of plate anchors buried in two layered sand. Geotechnique 40:293-297

6. Basudhar PK, Singh DN (1994) A generalized procedure for predicting optimal lower bound break-out factors of strip anchors. Géotechnique 44(2):307-318

7. Subba Rao KS, Kumar J (1994) Vertical uplift capacity of horizontal anchors. J Geotech Eng ASCE 120(7):1134-1147

8. Kumar J (2001) Seismic vertical uplift capacity of strip anchors. Geotechnique 51(3):275-279

9. Choudhury D, Subba Rao KS (2004) Seismic uplift capacity of strip anchors in soil. Geotech Geol Eng 22(1):59-72
10. Kumar J, Kouzer KM (2008) Vertical uplift capacity of horizontal anchors using upper bound limit analysis and finite elements. Can Geotech J 45:698-704

11. Ghosh P (2009) Seismic vertical uplift capacity of horizontal strip anchors using pseudo-dynamic approach. Comput Geotech 36(1-2):342-351

12. Ghosh P (2010) Seismic uplift capacity of inclined strip anchors in sand using upper bound limit analysis. Geomech Geoeng 5(4):267-275

13. Emirler B, Bildik S, Laman M (2014) Numerical investigation of anchor plates in layered soil. In: Proceedings of the 2nd international conference on advances in civil, structural and environmental engineering-ACSEE, pp 358-363

14. Hanna TH, Sparks R, Yilmaz M (1972) Anchor behaviour in sand. J Soil Mech. Found Div ASCE 98(11):1187-1207

15. Geddes JD, Murray EJ (1996) Plate anchor groups pulled vertically in sand. J Geotech Eng ASCE 122(7):509-516

16. Kumar J, Kouzer KM (2008) Vertical uplift capacity of a group of shallow horizontal anchors in sand. Geotechnique 58(10): 821-824

17. Kouzer KM, Kumar J (2009) Vertical uplift capacity of two interfering horizontal anchors in sand using an upper bound limit analysis. Comput Geotech 36:1084-1089

18. Ghosh P, Santhoshkumar G (2015) Vertical uplift capacity of two nearby horizontal strip anchors using method of stress characteristics. Int J Geomech ASCE. doi:10.1061/(ASCE)GM.19435622.0000493,04015015

19. Ghosh P, Kumari R (2012) Seismic interference of two nearby horizontal strip anchors in layered soil. Nat Hazards 63(2):789-804

20. Itasca Consulting Group (2006) Fast lagrangian analysis of continua in 3 dimensions (FLAC3D), Version 3.1, User's Guide, Minneapolis

21. Ghosh P (2011) Seismic interference effect of two nearby square footings. In: Geo-Frontiers 2011, ASCE, pp 352-361

22. Singh B, Mistri B (2011) A study on load capacity of horizontal and inclined plate anchors in sandy soils. Int J Eng Sci Technol 3(9):6914-6922 